\title{
O ALVORECER DA IMUNIZAÇÃO NO SÉCULO XXI
}

\author{
THE DAWN OF IMMUNIZATION IN THE 21ST CENTURY
}

\begin{abstract}
Lara Victória Pinheiro ${ }^{1}$, Francisco Paulo Dias Júnior ${ }^{1}$, Ivamara de Morais Silva ${ }^{1}$, Johanna Gabrielle Alves Câmara ${ }^{1}$, Laís Araújo Torres ${ }^{1}$, Ana Raquel Ferreira Maia ${ }^{1}$, Jeronimo Camilo Costa Cantidio ${ }^{1}$, Tâmira Carminda Thomás de Araújo Figueiredo ${ }^{1}$, Jamile Rodrigues Cosme de Holanda ${ }^{2}$

${ }^{1}$ Graduandos em Medicina pela Faculdade de Enfermagem e de Medicina Nova Esperança - FACENE/RN, Mossoró, Rio Grande do Norte.

${ }^{2}$ Professor Faculdade de Enfermagem e de Medicina Nova Esperança - FACENE/RN, Mossoró, Rio Grande do Norte.
\end{abstract}

\section{Info}

Recebido: 07/2020

Publicado: $11 / 2021$

DOI: 10.37951/2358-260X.2021v8i2.5869

ISSN: 2358-260X

\section{Palavras-Chave}

Doenças transmissíveis. Investimento.

Tecnologia.

Keywords:

Communicable diseases. Investment. Technology

\section{Resumo}

Desde muito tempo a sociedade sofre com enfermidades transmissíveis, as quais, por séculos, mataram milhões de pessoas por falta de tecnologia avançada em tratamentos e, principalmente, imunização. A partir do século XVIII até os dias atuais, muitos foram os avanços e descobertas no que concerne à vacinação, contribuindo para que inúmeras doenças fossem prevenidas e, até mesmo, erradicadas, melhorando a qualidade de vida da população. Analisar, por meio de uma revisão narrativa, o desenvolvimento cronológico, desde o surgimento até os dias atuais, das descobertas e avanços no que se refere ao campo da imunização, bem como, o impacto disso na vida da população do Brasil e do mundo. Por meio de uma inspeção bibliográfica da literatura, artigos publicados nos últimos 20 anos foram selecionados, operando as plataformas SCIELO e PUBMED como bases de dados, abordando os descritores "atualização", "vacinação", "imunização" e "inovação tecnológica" em português e inglês, adotando padrões de exclusão e inclusão, selecionando, assim, os trabalhos a serem utilizados no presente estudo. Após séculos de avanços e descobertas no campo da tecnologia da imunização, com a criação de campanhas e programas de vacinação, como o Programa Nacional de Imunização, no Brasil, de referência internacional; no ano de 2021 observou-se, com a incidência da pandemia de Covid-19, que assolou todo o mundo, a emergência da demanda para a formulação de vacinas contra esse agente, corroborando a importância dessa tecnologia e anunciando os novos desafios a serem superados. A elaboração de vacinas no século XXI é fruto de árduos investimentos, feitos durante anos, em tecnologias e pesquisas, objetivando o aperfeiçoamento na lapidação e amplificação das demandas por imunógenos, que aumentem, cada vez mais, a qualidade de vida da população. As vacinas configuram um instrumento indubitável para a conservação e desenvolvimento do processo saúde da população. Os avanços dessa tecnologia, bem como, a ampliação de investimentos, fazem-se de extrema necessidade ao que diz respeito à suplantação dos desafios que surgem a cada dia no tocante às doenças transmissíveis e imunopreveníveis.

\footnotetext{
Abstract

For a long time, society has suffered from communicable diseases, which, for centuries, killed millions of people due to the lack of advanced technology in treatments and, mainly, immunization. From the 18th century to the present day, there have been many advances and discoveries with regard to vaccination, contributing to innumerable diseases being prevented and even eradicated, improving the quality of life of the population. To analyze, through a narrative review, the chronological development, from the beginning to the present day, of the discoveries and advances regarding the field of immunization vaccines, as well as the impact of this on the quality of life of the population of the Brazil and the world. Through a bibliographic inspection of the literature, articles published in the last 20 years were selected, operating the SCIELO and PUBMED platforms as databases, addressing the keywords "update", "vaccination"," Immunization" and "technological innovation" in portuguese and english, adopting patterns of exclusion and inclusion, thus selecting the articles to be used in the present study. After centuries of advances and discoveries in the field of immunization technology, with the creation of campaigns and vaccination programs, such as the National Immunization Program, in Brazil, of international reference, in the year 2021 it was observed, with the incidence of the Covid-19 pandemic, which has plagued the world, the emergence of demand for the formulation of vaccines against this agent, corroborating the importance of this technology and announcing the new challenges to be overcome. The production of vaccines in the 21st century is the result of hard investments, made for years, in technologies and research, aiming at the improvement in the stoning and amplification of the demands for immunogens, which increase, more and more, the quality of life of the population. Vaccines are an undoubted instrument for the conservation and development of the population's health process. The advances in this technology, as well as the expansion of investments in it, are extremely necessary when it comes to overcoming the challenges that arise every day with regard to communicable and immunopreventable diseases.
} 


\section{INTRODUÇÃO}

A primeira vacina foi desenvolvida no ano de 1796 pelo médico britânico Edward Jenner, o material obtido foi oriundo das vacas, sendo intitulado como variolae vaccinae, vacina da varíola (DURÃES; OLIVEIRA; MONTEIRO, 2019). Em consequência da conquista na erradicação da varíola, estimulou a pesquisas pelos sanitaristas para a criação de novas vacinas para erradicar e controlar doenças imunopreveníveis (HOMMA et al, 2003).

Desde de então, muitos estudiosos passaram a desenvolver as vacinas, principalmente entre o final do século XIX e metade do século XX, tendo diferentes tipos de vacinas desenvolvidas, como a do sarampo, rubéola, caxumba, tuberculose, difteria, poliomielite e entre outras. Assim como a mudanças em vacinas já existentes, com objetivo de melhorar a qualidade das vacinas, sendo elas a tríplice viral (sarampo, caxumba, rubéola) e tríplice bacteriana (difteria, tétano, coqueluche) (HOMMA et al, 2011).

A partir do sucesso da vacinação contra a varíola, no ano de 1974 foi criado pela Organização Mundial de Saúde (OMS) o Programa Ampliado de Imunizações (PAI), que possibilitou a inserção de novos imunizantes em combate a doenças imunopreveníveis no cenário mundial (BRASIL, 2003).

Segundo dados da OMS, dos anos 2000 a 2007, as campanhas de vacinação contra o sarampo, possibilitaram a redução de $74 \%$ de mortes por esta doença. Em 2007 a vacinação da DTP (difteria, tétano e coqueluche) abrangeu uma cobertura de $80 \%$ da população. Com base nas seis regiões incluídas na OMS, três delas eliminaram a doença viral, poliomielite, em suas regiões. A partir dos dados apresentados, fundamenta a importância da vacinação e dos programas de imunização em cobertura da população mundial (HOMMA et al, 2011).
Neste cenário, a presente pesquisa busca compreender o processo de desenvolvimento das vacinas no século XXI, como também, o impacto da imunização na sociedade, por meio de uma revisão narrativa da literatura, sintetizando os resultados de diversos estudos, o desenvolvimento ao longo do tempo, desde o surgimento até os dias atuais, das descobertas e avanços no que se refere ao campo da imunização.

No cenário nacional, em suas últimas três décadas, apresenta uma estrutura de imunização da sociedade e da produção de vacinas com uma configuração extremamente eficaz, garantindo o controle de doenças infectocontagiosas no Brasil e no mundo. Concretizando a garantia dos princípios doutrinários do Sistema Único de Saúde (SUS), como a equidade e igualdade, tendo em vista o grande impacto dentro da classe mais pobre do país, sendo eles os mais acometidos pelas doenças transmissíveis.

\section{METODOLOGIA}

Para realização do presente trabalho, sob a forma de uma revisão narrativa, elegeu-se como fonte de conhecimento a pesquisa bibliográfica em artigos indexados na base de dados SCIELO e PUBMED, dos últimos 20 anos de produção científica, compreendendo o período de 2001-2021. Acrescido a este período, eventos históricos e marcantes no estabelecimento e desenvolvimentos de imunizantes. A escolha do período da pesquisa deu-se em decorrência a fatos importantes na história, dentre estes, o aniversário de 30 anos do Plano de Imunização, ocorrido em 2003, bem como do atual momento vivido com a pandemia da Covid 19.

A busca foi realizada pelos descritores, “atualização", "vacinação", "imunização" e "inovação tecnológica", de forma associada, usando o operador booleano "AND” e os filtros Brasil e saúde pública. 
Foram considerados todos os artigos com enfoque na área da saúde pública, sendo utilizado como critério de exclusão o período e a compatibilidade de conteúdo.

A busca dos descritores "atualização" e "vacinação", em todos os índices, com o operador booleano “AND” e os filtros Brasil e Saúde Pública, na base Scielo, resultou em 8 (oito) artigos. Já para os descritores "imunização" e "inovação tecnológica”, em todos os índices, com o operador booleano "AND" e os filtros Brasil e Saúde Pública, na base Scielo, resultou em 3 (três) artigos. Ao final, foram empregados 11 artigos, os quais encontram-se relacionados por código de identificação (DOI), título, autores e ano de publicação na bibliografia.

\section{RESULTADOS E DISCUSSÕES}

A demanda emergente para a produção de vacinas contra o Novo Coronavírus apontou para os novos desafios que o setor de produção e o alcance da imunização no cenário global. Além do emprego de novas tecnologias, mostrou-se a necessidade de as instituições estarem atentas ao domínio do conhecimento da produção dessa importante ferramenta de controle epidemiológico de doenças, o que fortaleceu o vínculo entre ciência e saúde, em um dos cenários mais desafiadores do século XXI.

\section{Acesso às vacinas no Brasil}

A campanha de erradicação da varíola oportunizou a criação do Programa Nacional de Imunizações no Brasil (PNI) emergindo a preocupação com a disponibilidade de imunobiológicos no controle de propagação de doenças. Dois anos após a fundação do PNI, em 30 de outubro de 1975, é promulgada a Lei 6.259, dispondo 'sobre a organização das ações de Vigilância Epidemiológica, sobre o Programa Nacional de Imunizações, estabelece normas relativas à notificação compulsória de doenças', dentre as normatizações, a de que vacinas obrigatórias seriam ofertadas gratuitamente pelo poder público e privado.

De acordo com Gadelha (2020), inicialmente o PNI disponibilizou vacinas para o combate a "difteria, tétano e coqueluche (DTP), poliomielite, tuberculose (BCG) e sarampo", obedecendo um calendário de vacinação pré-estabelecido pelo programa. Após a criação do Sistema Único de Saúde por meio da Constituição Federal de 1988, um número ainda maior de vacinas foi agregadas ao serviço, que tinha como desafio, vencer as barreiras geográficas em um país continental como o Brasil, garantir o acesso universal aos imunizantes, romper as limitações tecnológicas e conquistar/manter a confiança da população.

Em 2021, o Ministério da Saúde, tem préestabelecido em calendário nacional a oferta 14 vacinas, com cobertura em mais de 20 doenças, além desta previstas, estão em vigência ações de vacinação contra H1N1 e Sars-Cov-2, com aplicação mediante grupos e demanda de imunizantes.

É por meio do Programa Nacional de Imunizações que a sociedade brasileira pode contar com o acesso às vacinas. O Programa já fora reconhecido mundialmente por sua capacidade logística, pela inovação tecnológica e por ter em sua rede, a participação de instituições como FioCruz/ BioManguinhos e Butantã na produção nacional de imunizantes.

\section{Pesquisa, desenvolvimento e inovação de vacinas}

No século XVIII, Edward Jenner inicia o desenvolvimento da primeira vacina. No século XXI, com o advento de novas tecnologias, as vacinas avançaram em quantidade e complexidade. Gadelha (2020) ressalta que de vacinas com vírus atenuados, tidas como simples, evoluiu-se para vacinas multivalentes que utilizam cepas antigênicas do 
patógeno em circulação, como a da pneumonia e do papilomavírus humano (HPV).

A produção de vacinas deste século é resultado de investimentos maciços em pesquisas e tecnologia, visando o aprimoramento no desenvolvimento e na inovação às demandas por imunógenos. Segundo Griesenauer e Kinch (2017), os avanços na área foram frutos do trabalho do setor público, por meio de universidades, institutos e organizações não governamentais e sem fins lucrativos, e do setor privado, principalmente da indústria farmacêutica, sendo destaque a interação de ambos setores, onde "o Estado assume o risco nas fases mais básicas e incertas da inovação, e a indústria, nas etapas mais avançadas do desenvolvimento e na posterior introdução de novos produtos e processos no mercado" (GADELHA, 2020).

Neste contexto, Valentim et al. (2018) destaca que a predominância de capital financeiro do setor privado ainda é determinante na restrição de tecnologia, e por conseguinte, no norteamento das áreas de pesquisa e desenvolvimento, o que resulta em disparidades entre países e negligenciamento de determinadas doenças, pois o que predomina é a lógica financeira.

Visando dirimir as desigualdades e garantir o acesso às vacinas que seriam produzidas e comercializadas para o combate à pandemia da SarsCov-2, a Organização Mundial de Saúde (OMS) estabeleceu um mecanismo para obtenção e destinação de recursos públicos na busca da nova vacina. Para tanto, atribuiu a liderança executiva desta ação a $\mathrm{ONG}$ Global Alliance for Vaccine and Immunization - GAVI, fundada em 2000, com o intuito de garantir aos países pobres e muito pobres o acesso a imunizantes (GUIMARÃES, 2020).

Uma vez atribuída a missão do GAVI de tornar o acesso à vacina da Covid-19 menos desigual, a organização recebeu o apoio, além da OMS, de órgão multilaterais como Fundo das Nações Unidas para a Infância (UNICEF) e Banco Mundial, e de instituições provadas como a Fundação Gates e indústria biofarmacêutica. Dessa forma, surgiu a Global Vaccine Access Facility - Covax Facility, que ofertou aporte ao acesso e desenvolvimento de vacinas contra a Covid-19 em todo o mundo, onde de acordo com Guimarães (2020), ficou estabelecido a possibilidade de doações e subsídios de vacinas aos países pobres e muito pobres, financiamento público para desenvolvimento e produção de vacinas aos países de renda média e ricos, sob o compromisso de venda e doação das vacinas produzidas aos países pobres e muito pobres.

\section{Desenvolvimento de sistemas de controle de imunização}

Diante da importância da vacinação, há uma necessidade de controle de imunização de forma mais precisa, que possibilite lembretes em aparelhos digitais, como smartphones e tablets, tendo em vista que há alguns anos esse controle ocorria em carteiras/cadernetas, método este passível de esquecimento ou até mesmo perda da carteira de imunização.

Com o objetivo de evitar transtornos e manter o calendário de imunização sempre atualizado, foram criados alguns sistemas de controle de imunização. $\mathrm{O}$ aplicativo 'Vacinação em Dia' foi disponibilizado pelo Ministério da Saúde para o gerenciamento de cadernetas de vacinação cadastradas pelo usuário. No aplicativo são disponibilizadas informações completas das vacinas oferecidas pelo Sistema Único de Saúde (SUS), além de lembretes de campanhas sazonais de vacinação (BRASIL, 2021).

É possível adicionar cartões informando alguns dados como: nome, e-mail, celular, data de nascimento, sexo e se o usuário deseja receber notificações. 
Após o cadastro, o usuário pode “adicionar vacina", informando manualmente a vacinação que foi realizada, colocando dados como: data, lote, local e o tipo de imunizante, número da dose, etc. Além disso, é possível obter informações sobre uma determinada vacina, ao clicar no botão vacinas. O usuário terá acesso a uma lista de vacinas que estão organizadas de acordo com a faixa etária, desde o nascimento do indivíduo até a fase adulta.

O usuário pode, ainda, adicionar o lembrete de campanhas de vacinação, para que o processo de imunização coletiva seja efetivamente concluído. $\mathrm{O}$ objetivo principal do aplicativo é manter a população informada, oferecendo de forma simples informações para garantir a imunização do cidadão e de sua família.

Outro aplicativo que permite esse controle de imunização é o Meu digiSUS. Porém, não é a única funcionalidade do aplicativo. O digiSUS disponibiliza informações pessoais e clínicas contidas no Cadastro Nacional de Usuário do Sistema Único de Saúde (CADSUS), Portal do Cidadão, Corporativo e Cadastro Nacional de Estabelecimento de Saúde (CNES) (BRASIL, 2021).

O aplicativo funciona como uma espécie de prontuário médico, pois contém informações desde apresentação de exames de glicose, pressão arterial, avaliação nutricional até informações sobre transplantes do paciente. A página Minha Saúde mostra as informações gerais do cidadão como: lista de medicamentos que foram recebidos pelo programa 'Aqui tem Farmácia Popular', lista de vacinas recebidas e outras novidades.

O registro de vacinas pode ser acessado a partir do CPF do usuário. Também é possível verificar vacinas específicas para crianças, adultos, idosos e gestantes. O registro da informação cabe aos agentes de saúde que aplicam as vacinas nas Unidades Básicas de
Saúde no Sistema de Informações do Programa Nacional de Imunizações (SIPNEI).

\section{CONSIDERAÇÕES FINAIS}

Desenvolvidas há três séculos, as vacinas são um fator fundamental e indispensável à saúde da população mundial. Ao longo do desenvolvimento do texto, é possível destacar o quanto as vacinas foram imprescindíveis no combate de doenças avassaladoras como difteria, tétano, coqueluche, poliomielite, tuberculose e sarampo, doenças que hoje estão, basicamente, com seus índices controlados.

O Sistema Único de Saúde - SUS, sem dúvidas, é um grande aliado nas campanhas de vacinação do país. Superando o antigo programa de vacinação, PNI, o SUS representa uma maior acessibilidade às vacinas, fato esse que salvou e salva diversas vidas, principalmente de crianças, proporcionando a população uma melhor qualidade de vida.

Uma prova da qualidade do SUS se mostrou em face da pandemia do Covid-19. Os institutos de pesquisa parceiros desenvolveram as fórmulas e toda a distribuição de vacinas foi realizada pelo SUS, garantindo à população o acesso à saúde.

Portanto, diante do exposto, as vacinas representam um mecanismo indispensável para a manutenção de uma vida mais saudável. Demonstram também, o quanto se faz necessária à sua distribuição adequada e o quanto o sistema público de saúde, por meio do SUS, é um elemento crucial à sociedade brasileira.

\section{REFERÊNCIAS}

\section{BRASIL. Ministério da Saúde. Campanha Programa Nacional de Imunizações: Aplicativo Vacinação em Dia. Brasília: Ministério da Saúde, 2021. Disponível em: $<$ https://portalarquivos.saude.gov.br/campanh as/pni/>. Acesso em 16 maio 2021.}


Ministério da Saúde. Meu digiSUS. Brasília: Ministério da Saúde, 2021. Disponível em: $\quad<$ https://datasus.saude.gov.br/meudigisus-2/>. Acesso em 16 maio 2021.

Ministério da Saúde. Secretaria de Vigilância em Saúde. Programa Nacional de Imunizações 30 anos. Brasília: Ministério da Saúde, 2003. Disponível em: https://bvsms.saude.gov.br/bvs/publicacoes/li vro_30_anos_pni.pdf. Acesso em 16 maio 2021.

BRASIL. Presidência da República. Lei no 6.259, de 30 de outubro de 1975. Dispõe sobre a organização das ações de Vigilância Epidemiológica, sobre o Programa Nacional de Imunizações, estabelece normas relativas à notificação compulsória de doenças, e dá outras providências. Diário Oficial da União, Brasília, DF, 31 out. 1975.

DURÃES, Fabíola Alice dos Anjos; OLIVEIRA, Adriano Dias; MONTEIRO, Paulo Henrique Nico. Edward Jenner e a primeira vacina: estudo do discurso expositivo adotado em um museu de ciência. Khronos, $\mathrm{n}^{\circ}$ 7, pp. 1-15. 2019. Disponível em $<$ http://revistas.usp.br/khronos >. Acesso em: 16 maio 2021.

GADELHA, Carlos Augusto Grabois et al. Acesso a vacinas no Brasil no contexto da dinâmica global do Complexo Econômico-Industrial da Saúde. Cad. Saúde Pública, Rio de Janeiro, v. 36, supl. 2, e00154519, 2020. Disponível em: $<$ http://www.scielo.br/scielo.php?script=sci_a rttext\&pid=S0102-

$311 X 2020001405002 \& \operatorname{lng}=\mathrm{en} \& \mathrm{nrm}=\mathrm{iso}>$.

Acesso em: 15 maio 2021.

GADELHA, Carlos Augusto Grabois. Programa Nacional de Imunizações: o desafio do acesso universal no Século XXI. Ciênc. saúde coletiva, Rio de Janeiro, v. 25, n. 11, p. 4234, nov. 2020. Disponível em: $<$ http://www.scielo.br/scielo.php?script=sci_a rttext\&pid=S1413

$81232020001104234 \& \operatorname{lng}=$ en\&nrm $=$ iso $>$.

Acesso em: 15 maio 2021.

GRIESENAUER, Rebekah H.; KINCH, Michael S.. An overview of FDA-approved vaccines \& their innovators. Expert Review Of Vaccines, [S.L.], v. 16, n. 12, p. 1253-1266, 25 set. 2017. Informa UK Limited. Disponível em: $<$ https://pubmed.ncbi.nlm.nih.gov/28931331/ >. Acesso em: 15 maio 2021.
GUIMARAES, Reinaldo. Vacinas Anticovid: um Olhar da Saúde Coletiva. Ciênc. saúde coletiva, Rio de Janeiro, v. 25, n. 9, pág. 3579-3585, setembro de 2020. Disponível em: $<$ http://www.scielo.br/scielo.php?script=sci_a rttext\&pid=S1413-

$81232020000903579 \& \operatorname{lng}=$ en\&nrm $=$ iso $>$. Acesso em: 15 maio 2021.

HOMMA, Akira et al. Atualização em vacinas, imunizações e inovação tecnológica. Ciênc. saúde coletiva, Rio de Janeiro, v. 16, n. 2, p. 445-458, Feb. 2011. Disponível em: $<$ http://www.scielo.br/scielo.php?script=sci_a rttext\&pid=S1413-

$81232011000200008 \& \operatorname{lng}=$ en\&nrm $=$ iso $>$.

Acesso em: 16 maio 2021.

https://doi.org/10.1590/S1413-

81232011000200008 .

HOMMA, Akira et al. Desenvolvimento tecnológico: elo deficiente na inovação tecnológica de vacinas no Brasil. Hist. cienc. saúde-Manguinhos, Rio de Janeiro, v. 10, supl. 2, p. 671-696, 2003. Disponível em: $<$ http://www.scielo.br/scielo.php?script=sci_a rttext\&pid=S0104$59702003000500011 \& \operatorname{lng}=$ en\&nrm $=$ iso $>$. Acesso em: 16 maio 2021. https://doi.org/10.1590/S010459702003000500011.

LUHM, Karin Regina; WALDMAN, Eliseu Alves. Sistemas informatizados de registro de imunização: uma revisão com enfoque na saúde infantil. Epidemiol. Serv. Saúde, Brasília, v. 18, n. 1, p. 65-78, mar. 2009. Disponível em: $<$ http://scielo.iec.gov.br/scielo.php?script=sci _arttext\&pid $=$ S1679

49742009000100007\&lng $=$ pt\&nrm $=$ iso $>$. Acesso em: 15 maio 2021.

VALENTIM, Ricardo A. de Medeiros et al. Conectividade e digitalização no contexto da saúde global: um olhar para o futuro inspirado na saúde 4.0. In: Departamento do Complexo Industrial e Inovação em Saúde, Secretaria de Ciência, Tecnologia e Insumos Estratégicos, Ministério da Saúde, organizador. Avanços, desafios e oportunidades no Complexo Industrial da Saúde em serviços tecnológicos. Brasília: Ministério da Saúde; $2018 . \quad$ Disponível em: <http://bvsms.saude.gov.br/bvs/publicacoes/1 ivro_complexo_industrial_servicos_tecnologico s_web.pdf >. Acesso em: 15 maio 2021. 